\title{
РАЗВИТИЕ СИСТЕМЫ УПРАВЛЕНИЕ ПРОЕКТАМИ НА ОСНОВЕ ЦИФРОВЫХ СЕРВИСОВ
}

\section{DEVELOPMENT OF A PROJECT MANAGEMENT SYSTEM BASED ON DIGITAL SERVICES}

\section{A. Lukyanova}

Summary. The purpose of the article is to determine the features of project management through the use of digital services. The advantages of digital transformation of the project team's activities are highlighted: improved communication, the possibility of optimizing remote collaboration, increasing the level of control and detailing of the work performed.

Keywords: digital transformation, project management, digital services, digital management.

\author{
Лукьянова Анна Васильевна \\ Д.э.н., дочент, Финансовый университет при \\ Правительстве РФ, Москва \\ avlukyanova@yandex.ru
}

Аннотация. Цель статьи заключается в определении особенностей управления проектами за счет использования цифровых сервисов. Выделены преимущества цифровой трансформации деятельности проектной команды: улучшение коммуникации, возможности оптимизации удаленной совместной работы, повышение уровня контроля и детализации выполняемых работ.

Ключевые слова: цифровая трансформация, проектное управление, цифровые сервисы, цифровой менеджмент.

Как показали проведенные до сих пор исследования организационных изменений управления проектами, они могут быть как эволюционными, так и революционными, они могут охватывать всю организацию или только ее отдельные части [1, 3]. Масштаб анализируемых изменений позволяет предположить эволюционный характер исследуемой трансформации.

Организации, желающие добиться успеха в реализации перспективных и сложных проектов, берут на себя развитие методической поддержки управления проектами.

Внедрение цифровых сервисов в проектное управление подразумевает в первую очередь изменения в следующих направлениях:

- управленческие функции и их автоматизация,

- коммуникации в проекте на основе мессенджеров и цифровых платформ,

- использование облачных сервисов для совместной работы и хранения документации по проекту,

- наличие автоматизации специальных возможностей управления отдельных областями и процессами проекта, например, такими как риск менеджмент, управление качеством и поставками продукта,

- поддержка проектов в части сопутствующих функций: маркетинга, обеспечение закупок, администрирование и др. 
Улучшение коммуникаций за счет цифровых сервисов в сочетании с тенденцией к гибкому управлению проектами и развитием цифровой методологии открывает перспективы развития в сторону автономного, самоорганизующегося управления проектами.

Цифровые сервисы и платформы управления проектами стали повсеместно внедряться с момента, как цифровые технологии заняли место в бизнесе. Отслеживание результатов, постановка целей, управление временем и наблюдение за взаимодействием в команде на основе цифровых сервисов сокращает сроки проектов, повышая их маржинальность.

Цифровая трансформация и внедрение в управление проектами цифровых сервисов позволяет менеджерам проектов больше сосредоточиться на целостном мышлении и стратегическом планировании, а не на процессах. Руководители проектов могут делать больше с меньшими затратами, а это означает, что больше внимания уделяется результатам и меньше - процессной работе.

Стоит отметить, что управление проектами все больше основывается на анализе. С точки зрения ключевых показателей эффективности, цифровая трансформация в управлении проектами значительно увеличила использование числовых данных для управления проектами [4].

Анализ данных и прогресса по проектам на основе цифровых сервисов позволяет отслеживать и оценивать результаты с точки зрения бюджетов, рисков, качества, результатов проектов и, как следствие, рабочие процессы становятся более эффективны и результативны.

Наконец, проектные команды становятся более децентрализованными. Множество платформ управления проектами в сочетании с мессенджерами и видеоконференцсвязью и изменением рабочих процессов в результате внедрения цифровых сервисов позволяет управлять проектами в режиме удаленной работы.

В условиях пандемии удаленная работа стала вариантом, ограниченным только политикой компании. Это изменение стало ключевым для менеджеров проектов, которым в данных условиях необходимо сбалансировать работу по управлению проектами, максимально эффективно не сокращая при этом сроки реализации проектов. Цифровые сервисы позволяют сократить ощущения удаленность у команд проектов.

На отечественном и зарубежном рынке сегодня можно найти большое количество систем управления проектами и онлайн сервисов для организации управления проектами [2]. Они отличаются набором инструментов, стоимостью, удобствами интерфейсов и коммуникаций, наличием или отсутствием мобильного приложения и др.

Можно выделить следующие основные наиболее популярные и эффективные достоинства данных сервисов:

- ведение неограниченного количества задач, их привязка к исполнителям, формирование календарей и план графиков продуктов проектов, учет времени,

- всевозможные уведомления для команды проекта и пользователей конечного продукта проектов,

- корпоративные чаты с возможностью видео и аудиозаписи,

- интеграция с внешними системами компании, например финансовой, бухгалтерского и кадрового учета, почтовыми сервисами, облачными сервисами и документами,

- импорт и экспорт всевозможных данных необходимых для управления проектом или продуктом проекта,

- инструменты для детального анализа данных по проектам, построению всевозможных отчеTов,

- наглядные и простые в использовании доски для применения гибких методов управления в части постановки задач,

- инструменты для финансовой модели проекта и проектного бюджетирования,

- ведение деловых бесед, групповых бесед, работы с большой командой $100+$ человек,

- возможность синхронизации с любыми другими устройствами.

С учетом развития цифровых технологий изменения методологии управления проектами, наличия удаленных команд, развитие цифровых сервисов по управлению проектами будет только увеличиваться в ближайшее время. Тем не менее, процесс оптимизации и эффективного управления проектами не в использовании всех перечисленных инструментов, а в поиске оптимального сочетания возможностей цифровых сервисов для максимального удовлетворения пользователей продуктов проектов и повышении эффективности в управлении проектами.

Таким образом, выше представлены особенности управления проектами за счет использования цифровых сервисов. Выделены преимущества внедрения цифровых сервисов в управление проектами и цифровой трансформации деятельности проектной коман- 
ды. Преобразование - это не проект с датой начала и окончания. Обосновано, что использование цифровых сервисов - это долгосрочный процесс оптими- зации циклов управления, а также удовлетворения меняющихся потребностей клиентов, сотрудников и деловых партнеров.

\section{ЛИТЕРАТУРА}

1. Биряльцев Е.В., Галимов М.Р., Демидов Д.Е., Елизаров А.М. Цифровой проект и платформа для работы с ним // Вестник ЮУрГУ. Серия: Вычислительная математика и информатика. 2020. № 1. С. 50-68.

2. Боев А.Г., Воронин С.И. Использование SCRUM-метода при реализации проекта по внедрению цифровой платформы промышленного предприятия // Организатор производства. 2019. № 2. С. 16-26.

3. Иващенко А.В., Корчивой С.А., Сюсин И.А., Буканова Ю.В., Чуваков А.В. Автоматизированная система мониторинга проектов цифровой экономики // Модели, системы, сети в экономике, технике, природе и обществе. 2019. № 3. С. 94-103.

4. Корчивой С.А. Инфраструктурное развитие проектов цифровой экономики // Известия Самарского научного центра РАН. 2019. № 5. С. 73-82.
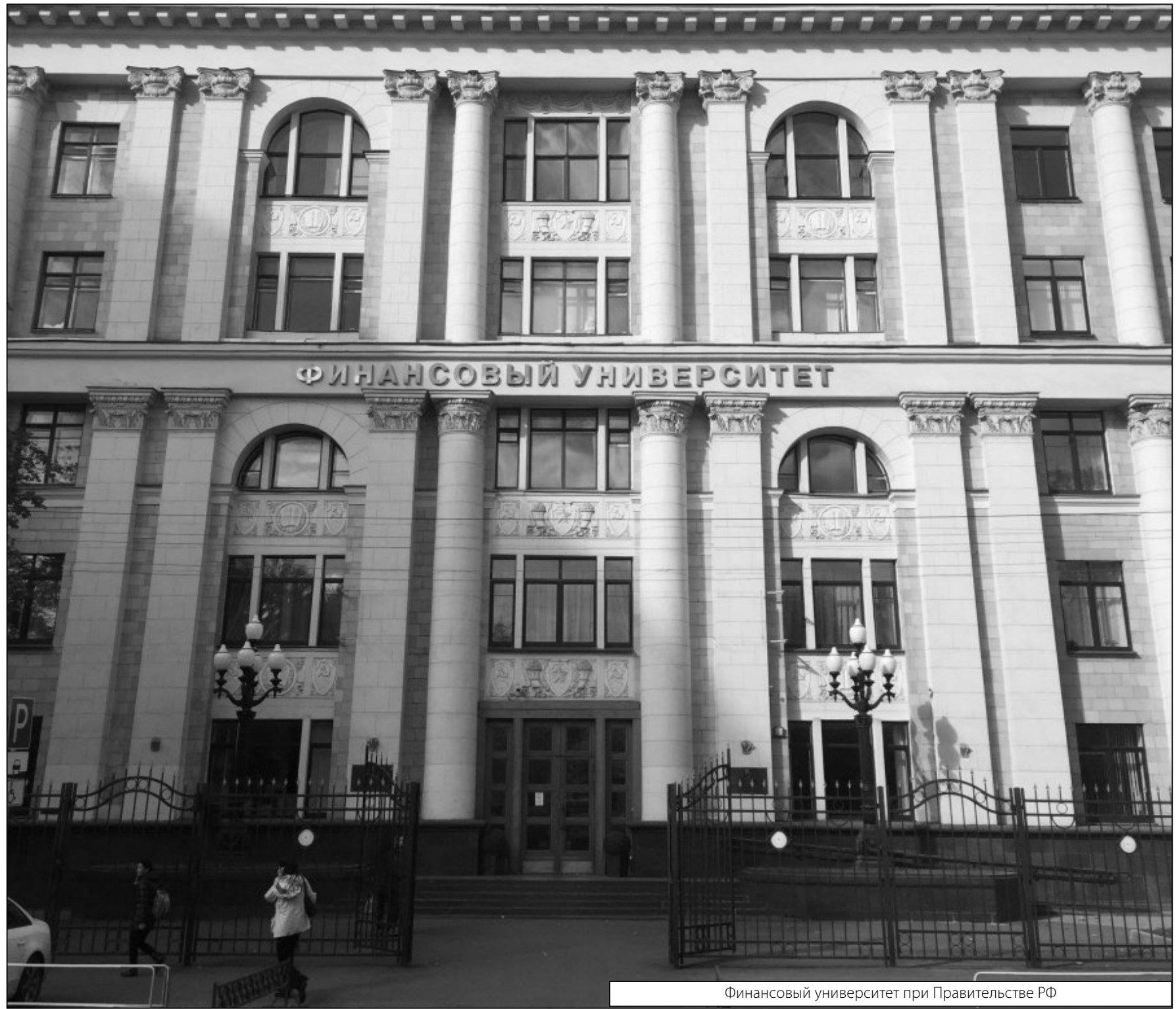